\title{
Phylogenetic analysis of marginal Asiatic black bears reveals a recent Iranian-Himalayan divergence and has implications for taxonomy and conservation
}

\author{
Gholam Hosein Yusefi ${ }^{1,2,3}$. Leili Khalatbari ${ }^{1,3} \cdot$ Michael J. Jowers $^{1} \cdot$ Hadi Fahimi $^{3} \cdot$ Vânia Costa $^{1} \cdot$ Mats Björklund $^{2}$. \\ Albano Beja-Pereira ${ }^{1,4}$
}

Received: 11 October 2019 / Accepted: 27 May 2020 / Published online: 25 June 2020

(C) The Author(s) 2020

\begin{abstract}
A small population of Asiatic black bear-known as the Baluchistan black bear—survives in the western limit of the species' range in Iran, where the species is rare, difficult to monitor and occupy an atypical habitat with extreme environmental conditions. Through the use of noninvasively collected samples, we analyzed mitochondrial DNA control region sequences to evaluate the phylogenetic relationships and divergence time between the Baluchistan Iranian black bear population and other Asian populations. Phylogenetic analyses indicate that Baluchistan and Nepalese (Himalayan) populations are monophyletic, with their divergence time estimated at circa 120 thousand years ago. The results reveal the low level of mitochondrial DNA variability in this small and marginal population, as is the case for many bear populations living in areas with similar conditions. The divergence time between the populations from Iran and Nepal dates to the Late Pleistocene, pointing to a transitional period between colder (glacial) and warmer (interglacial) conditions that allowed forests to expand and opened new habitats to population expansions. Pending further genetic and morphological corroboration, these preliminary results suggest that all Baluchistan and Himalayan (Nepalese) black bears might be considered as synonymous under the prior $U$. $t$. thibetanus trinomial (with gedrosianus just as junior synonym). Conservation efforts on this small and endangered population remain poor, and further measures are required to guarantee its long-term survival in Iran.
\end{abstract}

Keywords Baluchistan black bear $\cdot$ Ursus thibetanus gedrosianus $\cdot$ Himalayan black bear $\cdot$ Late pleistocene $\cdot$ Subspecies taxonomy $\cdot$ Ursus thibetanus

\section{Introduction}

The Asiatic black bear Ursus thibetanus Cuvier (1823) is widely distributed throughout Asia, ranging from the Manchuria Region in eastern Russia to Iran, in the southwestern

Handling editor: Paul Grobler.

Leili Khalatbari and Michael J. Jowers have contributed equally.

Hadi Fahimi deceased.

Electronic supplementary material The online version of this article (https://doi.org/10.1007/s42991-020-00044-8) contains supplementary material, which is available to authorized users.

Gholam Hosein Yusefi

gh.yusefi@cibio.up.pt

Extended author information available on the last page of the article part of this vast continent (Garshelis and Steinmetz 2016). Unlike their eastern Asian counterparts, the populations whose distribution area spans from China to Iran remain poorly studied. As such, it is not surprising that the genetic status of these populations is still hardly known; in contrast, genetic tools have been widely employed to study the eastern Asian populations (e.g., Saitoh et al. 2001; Ishibashi and Saitoh 2004; Ohnishi et al. 2007, 2009; Yasukochi et al. 2009; Choi et al. 2010; Kim et al. 2011; Uno et al. 2015; Wu et al. 2015). To date, only one study (Kadariya et al. 2018) has employed molecular markers to assess Asiatic black bear genetic diversity east from China. Interestingly, this study showed that the Nepalese Asiatic black bear population was in fact a distinct lineage and basal to all other mainland populations.

In Iran, Asiatic black bears are confined to small and isolated patches in the remote mountainous areas of the southeastern part of the country (Almasieh et al. 2016; Almasieh 
and Kaboli 2018; Farashi and Erfani 2018). This population, also known as the Baluchistan black bear, is the westernmost marginal population of the species, as well as one of the most threatened (Fahimi et al. 2011; Garshelis and Steinmetz 2016). Furthermore, not only is this population geographically marginal but it is also an ecologically marginal population. In the dry landscape and sparse woodlands of this area that are intersected by lowland deserts and wide plateaus, the bear inhabits a suboptimal habitat with extreme environment conditions that differs from the other parts of species' range in Asia (Yusefi 2013). Currently, this population is under severe threat, primarily by habitat loss and fragmentation, along with human persecution by human-bear conflicts (Ghadirian et al. 2017; Fahimi et al. 2018) and, therefore, it is listed as "Endangered" at a national level (Yusefi et al. 2019). Due to the scarcity of suitable habitat, it is believed that the Baluchistan black bear population may occur at very low densities with a population under 200 individuals, divided in scattered subpopulations, each only harboring a few individuals (Yusefi 2013). Despite this, the Baluchistan black bear is one of the least-known large mammals in the country and information and scientific data remains deficient, with a subsequent lack of efficient conservation measures (Yusefi 2013; Almasieh and Kaboli 2018).

The Baluchistan black bear was long considered as a distinct subspecies, U. t. gedrosianus (Blanford 1877). However, the taxonomic validity of $U$. t. gedrosianus is uncertain and the affinity of this population with that of other populations has not been tested with molecular methods (Kadariya et al. 2018). The latter can be particularly important since the taxonomy of Asiatic black bears below the species level remains uncertain, and there is no consensus with regard to either their systematics or their taxonomic nomenclature (Choi et al. 2010; Wu et al. 2015). In this study, we use noninvasively collected samples from Iran and published data from GenBank, to explore the phylogenetic relationship and divergence time of Baluchistan black bears in relation to other Asiatic black bear subspecies and provide insights into the subspecific taxonomy of the species throughout its range in Asia. To foresee management decisions and conservation planning there is a pressing need to assess the genetic status of small, fragmented and threatened populations.

\section{Materials and methods}

\section{Study sites, sampling and DNA extraction}

Baluchistan black bears were noninvasively sampled by collecting scats in six geographically separated areas: (1) Bahr-e Asman, (2) Dehbakri-Dalfard (Zaryab), (3) Kahnouj County and (4) Marz-Bashagard in Kerman Province, (5) Roudan County in Hormuzgan Province and (6) Nikshahr County in Sistan and Baluchistan Province (Fig. 1) (Yusefi

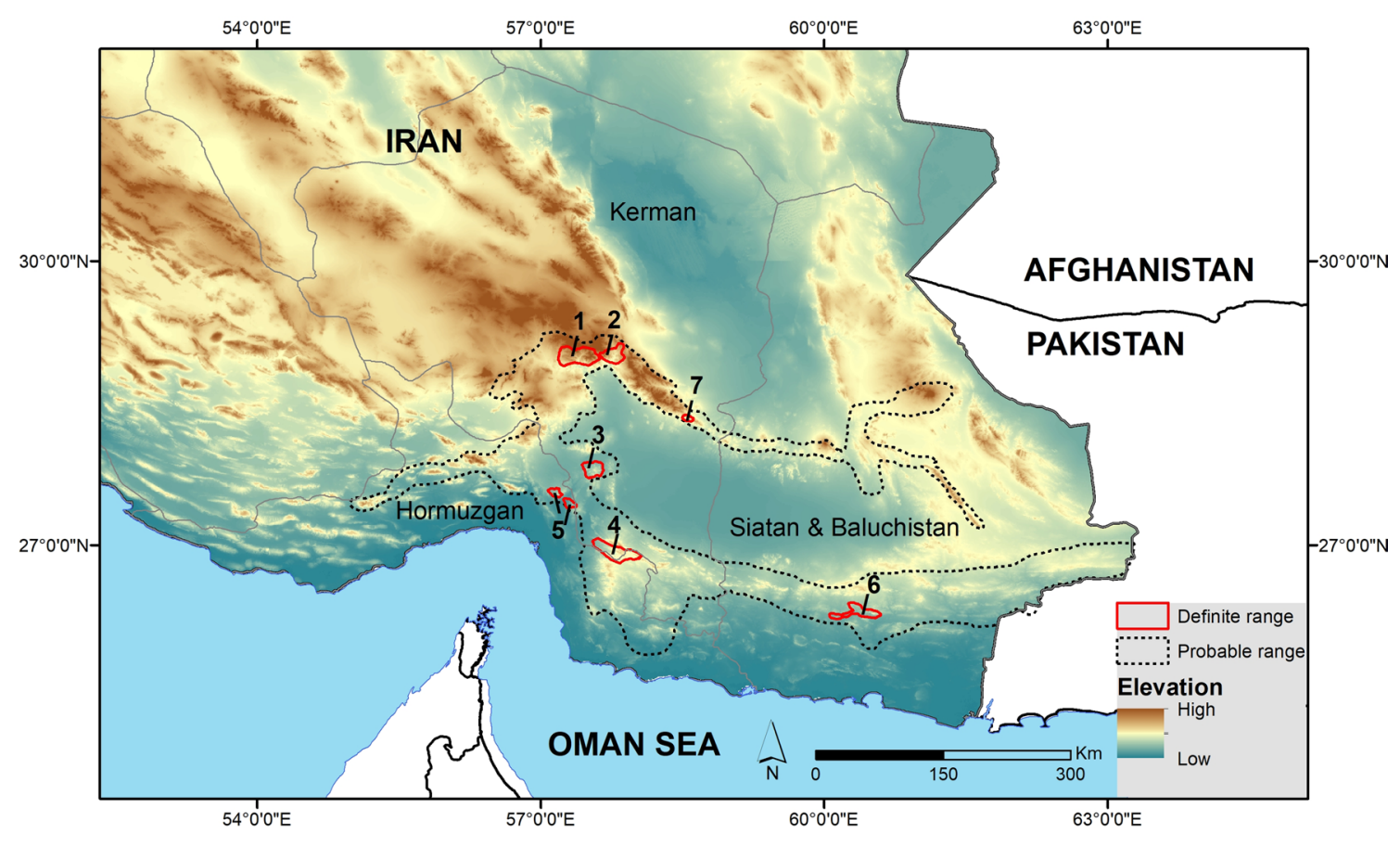

Fig. 1 Distribution range of Asiatic black bears in Iran (dashed line: probable range; solid red-color line: definite range). All the definite range areas including Bahr-e Asman (1), Dehbakri-Dalfard (Zaryab)
(2), Kahnouj County (3), Marz-Bashagard (4), Roudan County (5), and Nikshahr County (6) were sampled, with the exception of Jebal Barez (7) 
2013). Although the probable range of the species is wide, its presence has merely been confirmed in some localities in southeast Iran, and all these areas with the exception of Jebal Barez were sampled (Fig. 1). Overall, the average distance between localities was circa $180 \mathrm{~km}$ (distance; minimum $40 \mathrm{~km}$, maximum $500 \mathrm{~km}$ ). 218 fecal samples were collected opportunistically between 2008 and 2011 along animal trails, or from cave entrances and orchards, but only those believed to be fresh $(n=74)$ were used for genetic analysis. Besides the feces samples, two tissue samples belonging to dead individuals (from Dehbakri-Dalfard and Roudan) were also included in this study. Finally, one fresh scat sample from a captive bear (originally from Nikshahr area) was also included. Air-dried samples were stored inside a Ziploc plastic bag containing silica gel or in a container with pure ethanol until transferring to the Research Center in Biodiversity and Genetic Resources (CIBIO) (Porto, Portugal).

\section{DNA extraction and sequencing}

DNA extraction followed Costa et al. (2017) with overnight digestion with proteinase $\mathrm{K}$ and carried on a laminar flux chamber, physically isolated from the PCR room. The samples were processed in batches with a maximum of 16 samples per set. All the materials used for the extraction process was disinfected between samples and between all groups of samples as well. Negative controls were used to assess for contamination with each extraction batch.

We sequenced a $338 \mathrm{bp}$ fragment of the mtDNA control region $(\mathrm{CR})$ with primers UTCR1F (5'-CCTAAGACTAAG GAAGAAG-3') and UTCR2R (5'-TACTCGCAAGGATTG CTGG-3') (Miller et al. 2006). This short sequence was targeted due to bad preservation of samples and because it holds the highest variability of the CR (Yusefi 2013). In addition, two individuals (see results) were amplified for $680 \mathrm{bp}$ (which included the shorter $338 \mathrm{bp}$ ) with the same forward primer and the reverse primer (5'-CGTGTTCYY CGATTCAGTGGTATT-3', this study) to include in the phylogenetic analyses. PCR conditions were as described in Yusefi (2013). Thirty three sequences, which represent 19 individuals identified by probability of identity through microsatellite genotyping (Yusefi 2013) were used in this study.

\section{Data analyses}

Sequences were inspected and edited using Sequencer v5.4.6 (Gene Codes Corporation, Ann Arbor, MI, USA) and thereafter submitted to GenBank (under accession numbers MT432185-MT432186). Subspecies-level identification was performed using GenBank's BLASTn search (Altschul et al. 1990). Seaview v.4.2.11 (Gouy et al. 2010) was used for preliminary alignments of sequences and were aligned thereafter in MAFFT (Katoh et al. 2002), and phylogenetic analyses were conducted using $680 \mathrm{bp}$ alignment of the control region. The most appropriate substitution model $(\mathrm{KKY}+\mathrm{I})$ was determined according to the Akaike's Information Criterion (Akaike 1974) in jModeltest 2 (Posada 2008).

\section{Phylogenetic analysis and divergence time}

Phylogenetic analyses were conducted using Bayesian Inference (BI) in MrBayes v3.2.6 (Ronquist et al. 2012) and Maximum Likelihood (ML) in Garli v2.0.1 (Zwickl 2006). MrBayes was used with default priors and Markov chain settings, and with random starting trees. Each run consisted of four chains of 10 million generations, sampled every 10,000 generations. ML analysis was performed using 10 independent searches and 1000 bootstrap replicates. PAUP (Swofford 2002) was used to summarize non-parametric bootstrap support values for the best tree, after generating a majority-rule consensus tree. All analyses were performed using the CIPRES platform (Miller et al. 2010). Consensus tree inferred for each phylogenetic approach was visualized and rooted using FigTree v1.4.3 (Rambaut 2017).

We performed statistical coalescent and phylogeographic analyses using BEAST v1.8.3 (Drummond et al. 2012; https ://beast.bio.ed.ac.uk). We inferred a mitochondrial gene tree based on a constant coalescent model under the HKY + I model strict clock. To time-calibrate the population tree, we fixed the mutation rate in the control region to $2.9 \times 10^{-8}$ substitutions/site/year following Wu et al. (2015). This data set was much reduced to include only representative of all Asiatic black bears subspecies from Japan, Korea, Russia, Nepal, Taiwan, and China (downloaded from GenBank; Supplementary material, Table S1) and combined with haplotypes from Iran (this study). We ran two independent MCMC chains, each with 10 million generations and sampling every 10,000 generations. Independent runs were evaluated for convergence and mixing by observing and comparing traces of each statistic and parameter in Tracer v1.7 (Rambaut et al. 2018; https://beast.bio.ed.ac.uk/tracer). We considered effective sampling size (ESS) values $>200$ to be good indicators of parameter mixing. The first $20 \%$ generations of each run were discarded as burnin, and samples were merged using LogCombiner v1.8.3. The resulting chains were summarized using TreeAnnotator v1.8.3, where a maximum-clade-credibility (MCC) tree with mean values were generated under the "-heights ca" option (Heled and Bouckaert 2013).

Two median-joining networks were constructed in PopART, Bandelt et al. 1999; https://popart.otago.ac.nz) to assess the phylogenetic relationships of all known control region sequences available for Asiatic black bears (including translocated animals from captive centers and zoo animals 
with uncertain origin) and a smaller network with only animals from known origin (downloaded from GenBank; Supplementary material, Table $\mathrm{S} 1$ ). We include only two $U$. t. japonicus haplotypes to show the position of this highly divergent clade relative to the other subspecies. The larger and smaller network alignments had 121 and 88 sequences, respectively. However, total exclusion of sequences with considerable missing data resulted in 85 and 54 sequences, respectively.

\section{Results}

Two haplotypes differing by an indel were recovered from all Iranian samples (Supplementary material, Table S2). The longer control region sequences ( $680 \mathrm{bp}$ ) belonged to each of the two haplotypes, and despite a much increase sequenced length, they differed only by the same indel. The control region belonging to a Chinese specimen (GenBank accession No. DQ402478, the complete mitochondrial genome) was highly divergent to all mainland $U$. thibetanus subspecies and even more divergent than U. t. japonicus. The GenBank blast searchers of the control region sequence matched $U$. americanus (Pallas 1780) with 98\% identity (as it has been reported previously by Wu et al. 2015), despite the authors reporting a $90 \%$ similarity to the complete control region (1422 bp) of the American black bear (Hou et al. 2007). The origin on this sequence derives from Asiatic black bears collected from Sichuan Province Traditional Chinese Medicinal
Materials Company and, therefore, may suggest either an unknown sample or cross contamination. Following these results, we did not name this subspecies in our analyses $U$. t. mupinensis (unlike analyses including its complete mitochondrial genome, Wu et al. 2015; Kadariya et al. 2018) and was excluded from the phylogenetic analyses.

The large network recovered Taiwanese, Chinese, Vietnamese, and Korean samples scattered throughout, with no evident structure or distribution patterns in relation to current distribution suggesting mixture of Asiatic black bears in recovery centers and zoos (Supplementary material, Fig. S1). The smaller network that excluded all those likely mixed individuals with uncertainty in the locality of origin (from zoos, recovery centers, or introduced animals) recovered five well-distinguishable $U$. thibetanus clusters (subspecies groups), in accordance with Kadariya et al. (2018) with the exception of differences in nominotypical subspecies (discussed below) (Fig. 2). Similarly, difference in the alignments to Kadariya et al. (2018) resulted in different clusters in both networks. The sequence belonging to FM177759 was recovered in the smaller network between the Baluchistan and Nepalese black bears (Fig. 2), but its origin is unknown. Its high divergence to any other haplotype suggests that this could belong to a different subspecies. Two sequences (EF587265, KT964290) have ambiguous placement in the networks. The former is labeled as U. t. thibetanus in GenBank with unknown geographical origin, and the latter is a sequence from China, which grouped with Far East populations in Russia and Korea. The MCC tree and BI tree

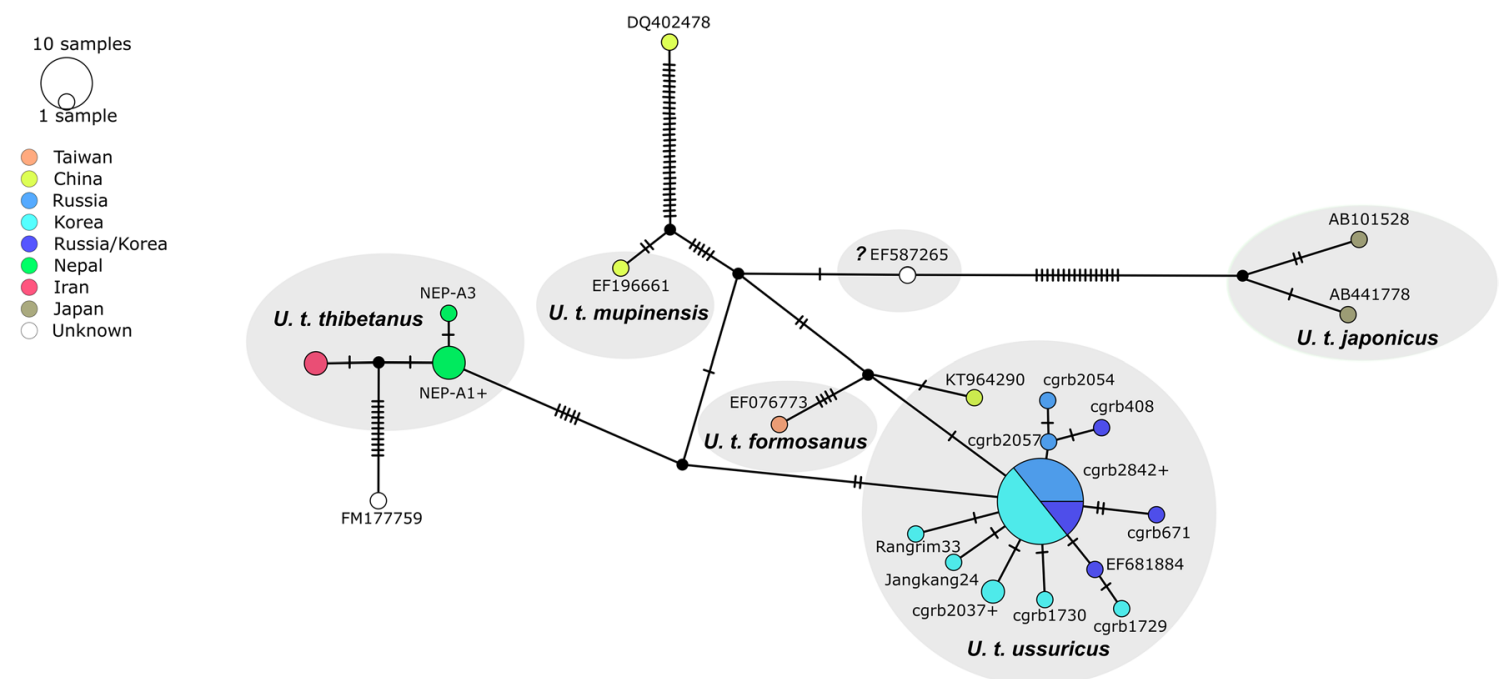

Fig. 2 Median-joining network of 54 Ursus thibetanus mtDNA control region sequences from mainland Asia and Taiwan with known locality of origin. Two U. t. japonicus haplotypes are included to show the position of this highly divergent clade relative to the other subspecies. The circles indicate individual haplotypes, and their sizes are proportional to the frequency of the haplotypes. Shared haplotypes (+) are as follows: cgrb2842 plus haplotypes from Russia (cgrb2056, cgrb2058-2060, cgrb838-842), Korea (cgrb54, crgb1728, cgrb2034-2036, cgrb2038-2041, Songwon43, Jangkang21, Duksung16, FJ895267, EF667005), and Russia/Korea (cgrb2055, cgrb672, cgrb843, cgrb2053); cgrb2037 plus a haplotype from Korea (Songwon9); NEP-A1 plus other haplotypes from Nepal (MG066704, MH281753, NEP-A2). Coding follows GenBank vouchers, when not available the GenBank accession number is used instead (Detailed information on haplotypes is given in Supplementary material, Table S1) 


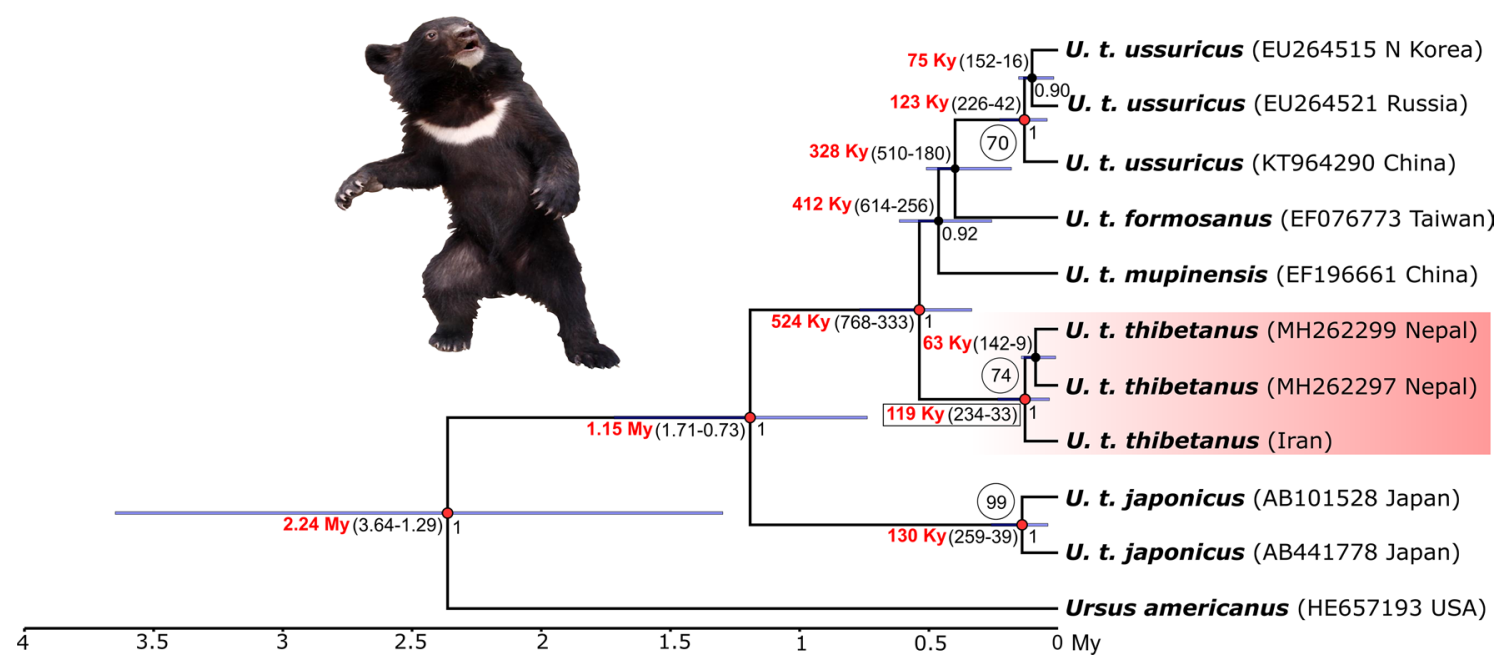

Fig. 3 BEAST tree of the control region sequences $(680 \mathrm{bp})$ of Asian black bear subspecies. The red clade represents Baluchistan and Nepalese $U$. thibetanus. The numbers at nodes (in red) indicate mean ages in Ky (Thousand years ago) and My (Million years ago) and in brackets the $95 \%$ highest posterior density. The red nodes indicate posterior probability of 1 for the MCC tree. Bayesian inference pos- terior probability values are indicated at the bottom right of the nodes $(>0.9)$ and maximum likelihood bootstrap support $(>70 \%)$ in open circles by nodes. Terminal taxa are indicated by accession numbers. Detailed information on haplotypes is given in Supplementary material, Table S1. Photo credit: F. Heydari

Eurasia following changes in climate from an interglacial period (characterized by the expansion of forests and animals, also known as Eemian or Riss-Würm interglacial), to a glaciation period (Hofreiterl and Stewart 2009). This interglacial period (130-115 Ky, MIS 5-2) was a period of warmer conditions that allowed forests to expand and replace tundra at higher latitudes, and opened new habitats to population expansions (Helmens 2013). Following the last glacial period, ice-cover throughout the Himalaya likely acted as a geographic barrier (Lei et al. 2014) that subdivided ancestral populations and led to genetic divergence. Consequently, this likely resulted in a constricted distribution of the Asiatic black bears into refugial areas, contributing to isolation of western populations that lived at the periphery of the subspecies range. Nevertheless, the dating range of the time since most recent common ancestor (TMRCA) of both populations falls within glacial and interglacial conditions (95\% HPD: 234-33 Ky) and, therefore, accurate climatic conditions of such expansion (colder or warmer periods) cannot be postulated with confidence. Interestingly, fossil remains of the species (U. t. mediterraneus and U. t. permjak) have been found in the Caucasus and Europe dating to the middle Pleistocene (Baryshnikov 2010). These fossil records suggest that there have been several colonization events, most likely at interglacial periods towards the West.

The genetic diversity in Baluchistan black bears contrasts that of brown bears in Iran, which has been shown to be highly variable in terms of maternally inherited mtDNA (Ashrafzadeh et al. 2016). Unlike brown bears, the sampling recovered the lowest mitochondrial control region diversities 
reported in all the Asiatic black bears. Low mitochondrial genetic diversity in Baluchistan black bears may not be surprising as similar low-nucleotide diversity of mtDNA of the source population in the Himalayas has been previously reported (Kadariya et al. 2018), where only 3 haplotypes were recovered from 60 individuals. This can be partly explained by limited female-mediated gene flow as a result of female philopatry (female bears disperse and establish territories near their mothers) (Waits et al. 1998; Ohnishi and Osawa 2014) and/or by the small number of founders, as observed in the same species (Ishibashi and Saitoh 2004; Ohnishi et al. 2007, 2009) and other bears (e.g., Zachos et al. 2008; Pérez et al. 2009; Swenson et al. 2011; but see Murphy et al. 2015, 2018, 2019). However, we admit that maternally inherited mtDNA markers may not be (and often are not) appropriate for making inferences about levels of genetic diversity/exchange at the population-level, because the species (as bears do in general) is characterized by male-biased dispersal (Waits et al. 1998). This is especially true when considering the fact that the dispersal of female bears to areas of marginal quality as those occupied by Baluchistan black bear habitat is very unlikely. An alternative explanation could be the decline of the population. Anthropogenic activities are known to have reduced Baluchistan black bear distributions and demographics (Yusefi 2013). Increasing sample sizes from less-sampled areas might challenge the current data for those areas, with the finding of additional haplotypes. Nevertheless, given the extremely small population of Baluchistan black bears in Iran $(<200$ individuals), it likely represents most of the population genetic diversity. Furthermore, this sample size is also related to rareness of the species and sampling restrictions in remote and somehow unstable regions. It would be necessary to study the genetic diversity using other type of markers such as microsatellites, SNPs, etc., as such markers would allow us to better understand the genetic status of this endangered population.

\section{Subspecies classification and taxonomy implications}

Monophyly of Baluchistan + Nepalese populations questioning the validity of the $U$. t. gedrosianus subspecies described by Blanford (1877), calls for nominal taxonomic re-assessment and suggests that $U$. t. gedrosianus and the subspecies from central Nepal should be considered a single subspecies. A recent study (Kadirya et al. 2018) assigned the population from central Nepal to U. t. laniger (Pocock 1932), despite the fact that the correct name for Nepal populations should be $U$. t. thibetanus (Cuvier 1823) as it outlined by Pocock (1932). According to Pocock (1932), the range of the typical U. t. thibetanus includes Nepal (Terai: lowland belt that lies south of the outer foothills of the Himalayas) and extends to Myanmar and possibly southern China. Here, he also described $U$. t. laniger to the type locality in Kashmir, where Pakistan, India, and China meet and not Nepal or Bhutan as considered by Lan et al. (2017) and Kadirya et al. (2018). Indeed, the Asiatic black bear (U. thibetanus) was first found in the early nineteenth century in the mountains of Nepal (Cuvier 1823). However, Cuvier failed to assign a type locality for that taxon. Later, Pocock in 1932 allocated the typical thibetanus to Sylhet in Assam (northeastern India), because Cuvier gave the name thibetanus to a bear from that district. From this, we recognize thibetanus as the valid name for the Nepal population but not laniger. In the light of our results (i.e. monophyly of Baluchistan + Nepalese populations), and depending on further studies using autosomal nuclear markers (microsatellites and SNPs), and morphology, these two black bear populations might be considered as synonymous under the prior $U$. t. thibetanus trinomial (with gedrosianus just as junior synonym) as prescribed by the rules of the International Code of Zoological Nomenclature (ICZN), (ICZN 1999). Last, it is unclear as to which subspecies the population from Pakistan (Lan et al. 2017) belongs to; however, the preliminary analysis of the short control region $(180 \mathrm{bp})$ fraction was identical to the Iranian haplotype. Most importantly, our study supports new evidence for only five subspecies (thibetanus, formosanus, japonicus, mupinensis, and ussuricus) rather than seven, as suggested by previous works (e.g. IUCN; Wozencraft 2005).

\section{Conservation implications}

Despite once considered locally extinct and rediscovered in the 1970s, the Baluchistan black bear has received little attention from the Iranian Department of Environment (DoE), a legal entity responsible for issuing the national directives for environment and wildlife protection. Limited surveys have been carried out for the species and most of its range remains unprotected. Conservation for this endangered species is rarely enforced, even though this species is currently classified as "protected" by national Iranian law (Yusefi et al. 2010; Yusefi 2013). Worryingly, over the past decades the distribution of this bear has been reduced, becoming locally extinct in some areas (e.g., Khabr National Park and Birk Protected Area) (Ziaie 2008). Furthermore, because of the scarcity of suitable habitat, distribution patchiness, and geographically separated subpopulations, it is very likely that these areas hold only a few individuals. Such fragile subpopulations are at risk due to both genetic impoverishment and demographic threats. Immediate conservation actions such as reducing human-bear conflict, designation of new protected areas and protection of corridor habitats may help these small subpopulations survive.

Even with limited sampling, our study sheds light on the phylogenetic affinity of Baluchistan black bears, and (to some extent) on the taxonomy of Asiatic black bears below 
the species level, as well as providing a genetic benchmark for future molecular analyses of one of the least-known populations of the black bears in Asia. Nevertheless, we do recognize that our results should be considered with caution due to the limitations of our study.

Acknowledgements Open access funding provided by Uppsala University. We thank M. Chalani, M.E. Sehhatisabet, S. Broomand and the game guards of the DoE provincial offices in Kerman, Sistan and Baluchistan and Hormuzgan for all supports and helps during our field work. We would also like to thank two anonymous reviewers of an early version of this manuscript for their helpful comments. We also thank B. Zehzad, B.H. Kiabi, H. Ziaie and D. Garshelis for the priceless insight and advice during the first years of this study. This work is dedicated to the memory of our colleague/coauthor Hadi Fahimi, who was deeply committed to conservation of wildlife in Iran, especially black bears.

Funding GHY, LKH, VC, and MJJ are supported by the Portuguese Foundation of Science and Technology (FCT) (PD/ BD/52605/2014, PD/BD/132429/2017, SFRH/BD/88129/2012, SFRH/ $\mathrm{BPD} / 109148 / 2015$, respectively). ABP is supported by an IF contract from the FCT. This study was partially supported by a grant from Global Environment Facility (GEF)/Small Grants Programme (SGP)/ United Nations Development Programme (UNDP) (IRA/SGP/OP5/Y2/ STAR/BD/12/01(167)).

\section{Compliance with ethical standards}

Conflict of interest The authors declare no conflict of interest.

Open Access This article is licensed under a Creative Commons Attribution 4.0 International License, which permits use, sharing, adaptation, distribution and reproduction in any medium or format, as long as you give appropriate credit to the original author(s) and the source, provide a link to the Creative Commons licence, and indicate if changes were made. The images or other third party material in this article are included in the article's Creative Commons licence, unless indicated otherwise in a credit line to the material. If material is not included in the article's Creative Commons licence and your intended use is not permitted by statutory regulation or exceeds the permitted use, you will need to obtain permission directly from the copyright holder. To view a copy of this licence, visit http://creativecommons.org/licenses/by/4.0/.

\section{References}

Akaike H (1974) A new look at the statistical model identification. IEEE Trans Autom Contr 19(6):716-723

Almasieh K, Kaboli M, Beier P (2016) Identifying habitat cores and corridors for the Iranian black bear in Iran. Ursus 27:18-30

Almasieh K, Kaboli M (2018) Assessment of landscape connectivity and prediction of migration corridors for the Baluchistan black bear (Ursus thibetanus gedrosianus Blanford, 1877) in the southeastern habitats. Iran Iranian J Appl Ecol 8(1):33-45 (in Persian)

Altschul SF, Gish W, Miller W, Myers EW, Lipman DJ (1990) Basic local alignment search tool. J Mol Biol 215(3):403-410

Ashrafzadeh MR, Kaboli M, Naghavi MR (2016) Mitochondrial DNA analysis of Iranian brown bears (Ursus arctos) reveals new phylogeographic lineage. Mamm Biol 81:1-9

Bandelt H, Forster P, Röhl A (1999) Median-joining networks for inferring intraspecific phylogenies. Mol Biol Evol 16(1):37-48
Baryshnikov GF (2010) Middle Pleistocene Ursus thibetanus (Mammalia, Carnivora) from Kudaro caves in the Caucasus. Proc Zool Inst Russ Acad Sci 314:67-79

Choi H, Kim SK, Ryu SH, Jang KH, Hwang UW (2010) Mitochondrial genome phylogeny among Asiatic black bear Ursus thibetanus subspecies and comprehensive analysis of their control regions. Mitochondrial DNA 21:105-114

Costa V, Rosenbom S, Monteiro R, O'Rourke SM, Beja-Pereira A (2017) Improving DNA quality extracted from fecal samples-a method to improve DNA yield. Eur J Wildl Res 63:3. https://doi. org/10.1007/s10344-016-1058-1

Cuvier G (1823) Recherches sur les ossemens fossiles, où l'on rétablit les caractères de plusieurs animaux dont les révolutions du globe ont détruites les espèces. T.4. Paris, Chez G. Dufour et E. D'Ocagne, Libraires, et a Amsterdam, chez les mèmes (in French)

Davison J, Ho SYW, Bray SC, Korsten M, Tammeleht E, Hindrikson M, Østbye K, Østbye E, Lauritzen SE, Austin J, Cooper A, Saarma U (2011) Late-Quaternary biogeographic scenarios for the brown bear (Ursus arctos), a wild mammal model species. Quat Sci Rev 30:418-430

Drummond AJ, Suchard MA, Xie D, Rambaut A (2012) Bayesian phylogenetics with BEAUti and the BEAST 1.7. Mol Biol Evol 29:1969-1973

Farashi A, Erfani M (2018) Modeling of habitat suitability of Asiatic black bear (Ursus thibetanus gedrosianus) in Iran in future. Acta Ecol Sin 38:9-14

Fahimi H, Yusefi GH, Madjdzadeh SM, Damangir AA, Sehhatisabet ME, Khalatbari L (2011) Camera traps reveal use of caves by Asiatic black bears (Ursus thibetanus gedrosianus) in southeastern Iran. J Nat Hist 45:2363-2373

Fahimi H, Qashqaei A, Chalani M, Asadi Z, Brromand S, Ahmadi N, Yusefi GH (2018) Evidence of seed germination in scats of the Asiatic black bear Ursus thibetanus in Iran (Mammalia: Carnivora). Zool Middle East 64(2):182-184

Garshelis D, Steinmetz R (2016) Ursus thibetanus (errata version published in 2017). The IUCN red list of threatened species 2016: e.T22824A114252336. https://doi.org/10.2305/IUCN. UK.2016-3.RLTS.T22824A45034242.en. Accessed Aug 2019

Ghadirian T, Qashqaei AT, Soofi M, Abolghasemi H, Ghoddousi A (2017) Diet of Asiatic black bear in its westernmost distribution range, southern Iran. Ursus 28:15-19

Gouy M, Guindon S, Gascuel O (2010) SeaView version 4. A multiplatform graphical user interface for sequence alignment and phylogenetic tree building. Mol Biol Evol 27:221-224

Heled J, Bouckaert R (2013) Looking for trees in the forest: summary tree from posterior samples. BMC Evo Bio 13:221. https://doi. org/10.1186/1471-2148-13-221

Helmens KF (2013) The Last Interglacial-Glacial cycle (MIS 5-2) reexamined based on long proxy records from central and northern Europe. Technical report TR-13-02. Svensk Kärnbränlehantering AB, Swedish Nuclear Fuel and Waste Management Company. $1-59$

Hofreiter M, Stewart J (2009) Ecological change, range fluctuations and population dynamics during the Pleistocene. Curr Biol 19:584-594

Hou WR, Chen Y, Wu X, Hu JC, Peng ZS, Yang J, Tang ZX, Zhou CQ, Li YM, Yang SK, Du YJ, Kong LL, Ren ZL, Zhang HY, Shuai S (2007) A complete mitochondrial genome sequence of Asian black bear Sichuan subspecies (Ursus thibetanus mupinensis). Int J Biol Sci 3:85-90

International Commission on Zoological Nomenclature., Ride WDL, International Trust for Zoological Nomenclature, Natural History Museum (London England), International Union of Biological Sciences. General Assembly. 1999. International code of zoological nomenclature $=$ Code international de nomenclature 
zoologique. London: International Trust for Zoological Nomenclature. pp xxix, 306.

Ishibashi Y, Saitoh T (2004) Phylogenetic relationships among fragmented Asian black bear (Ursus thibetanus) populations in western Japan. Conserv Genet 5:311-323

Kadariya R, Shimozuru M, Maldonado JE, Moustafa MAM, Sashika M, Tsubota T (2018) High genetic diversity and distinct ancient lineage of Asiatic black bears revealed by non-invasive surveys in the Annapurna Conservation Area, Nepal. PLoS ONE 13(12):e0207662. https://doi.org/10.1371/journal.pone.0207662

Katoh K, Misawa K, Kuma K, Miyata T (2002) MAFFT: a novel method for rapid multiple sequence alignment based on fast Fourier transform. Nucleic Acids Res 30:3059-3066

Kim YK, Hong YJ, Min MS, Kim KS, Kim YJ, Voloshina I, Myslenkov A, Smith GJD, Cuong NDI, Tho HH, Han SH, Yang DH, Kim CB, Lee H (2011) Genetic status of Asiatic black bear (Ursus thibetanus) reintroduced into South Korea based on mitochondrial DNA and microsatellite loci analysis. J Hered 102:165-174

Lan T, Gill S, Bellemain E, Bischof R, Nawaz MA, Lindqvist C (2017) Evolutionary history of enigmatic bears in the Tibetan Plateau-Himalaya region and the identity of the yeti. Proc R Soc B 284:20171804. https://doi.org/10.1098/rspb.2017.1804

Lei F, Qu Y, Song G (2014) Species diversification and phylogeographical patterns of birds in response to the uplift of the QinghaiTibet Plateau and Quaternary glaciations. Curr Zool 60:149-161

Miller CR, Waits LP, Joyce P (2006) Phylogeography and mitochondrial diversity of extirpated brown bear (Ursus arctos) populations in the contiguous United States and Mexico. Mol Ecol 15:4477-4485

Miller, MA, Pfeiffer W, Schwartz T (2010) Creating the CIPRES Science Gateway for inference of large phylogenetic trees. In: Gateway computing environments workshop (GCE), pp 1-8

Murphy SM, Cox JJ, Clark JD, Augustine BC, Hast JT, Gibbs D, Strunk M, Dobey S (2015) Rapid growth and genetic diversity retention in an isolated reintroduced black bear population in the central Appalachians. J Wildl Manage 79:807-818

Murphy SM, Laufenberg JS, Clark JD, Davidson M, Belant JL, Garshelis DL (2018) Genetic diversity, effective population size, and structure among black bear populations in the Lower Mississippi Alluvial Valley, USA. Conserv Genet 19:1055-1067

Murphy SM, Hast JT, Augustine BC, Weisrock DW, Clark JD, Kocka DM, Ryan CW, Sajecki JL, Cox JJ (2019) Early genetic outcomes of American black bear reintroductions in the Central Appalachians, USA. Ursus 29:119-133

Ohnishi N, Saitoh T, Ishibashi Y, Oi T (2007) Low genetic diversities in isolated populations of the Asian black bear (Ursus thibetanus) in Japan, in comparison with large stable populations. Conserv Genet 8:1331-1337

Ohnishi N, Uno R, Ishibashi Y, Tamate HB, Oi T (2009) The influence of climatic oscillations during the Quaternary Era on the genetic structure of Asian black bears in Japan. Heredity 102:579-589

Ohnishi N, Osawa T (2014) A difference in the genetic distribution pattern between the sexes in the Asian black bear. Mamm Study 39(1):11-16

Pérez T, Vázquez F, Naves J, Fernández A, Corao A, Albornoz J, Domínguez A (2009) Non-invasive genetic study of the endangered Cantabrian brown bear (Ursus arctos). Conserv Genet 10:291-301

Pocock RI (1932) The black and brown bears of Europe and Asia. Part II. The sloth bear (Melursus), the Himalayan black bear
(Selenarctos) and the Malayan bear (Helarctos). J Bombay Nat Hist Soc 36(1):101-138

Posada D (2008) jModelTest: phylogenetic model averaging. Mol Biol Evol 25:1253-1256

Rambaut A (2017) FigTree v1.4.3. Available at http://tree.bio.ed.ac. uk/software/figtree. Accessed July 2019

Rambaut A, Drummond AJ, Xie D, Baele G, Suchard MA (2018) Tracer v1.7. Available at http://beast.bio.ed.ac.uk/tracer/. Accessed July 2019

Ronquist F, Teslenko M, van der Mark P, Ayres DL, Darling A, Höhna S, Larget B, Liu L, Suchard MA, Huelsenbeck JP (2012) MrBayes 3.2: efficient Bayesian phylogenetic inference and model choice across a large model space. Syst Biol 61(3):539-542

Saitoh T, Ishibashi Y, Kanamori H, Kitahara E (2001) Genetic status of fragmented populations of the Asian black bear Ursus thibetanus in western Japan. Popul Ecol 43:221-227

Swenson JE, Taberlet P, Bellemain E (2011) Genetics and conservation of European brown bears Ursus arctos. Mammal Rev 41:87-98

Swofford DL (2002) Phylogenetic analysis using parsimony (*and Other Methods). Version 4. Sinauer Associates, Sunderland, Massachusetts

Yasukochi Y, Nishida S, Han SH, Kurosaki T, Yoneda M, Koike H (2009) Genetic structure of the Asiatic black bear in Japan using mitochondrial. J Hered 100:297-308

Yusefi GH, Fahimi H, Broomand S, Saremi S, Allahgholi MA, Khalatbari L (2010) The Asiatic black bear (Ursus thibetanus) status and habitat use in Jiroft Region, Kerman Province, Iran. Mohitban Society, Tehran, Iran; Report submitted to the Department of Environment, Kerman Provincial Office, Iran. (in Persian)

Yusefi GH (2013) Noninvasive genetic tracking of Asiatic black bears (Ursus thibetanus) at its range edge in Iran: a pilot study. MSc Dissertation, Uppsala University, Sweden

Yusefi GH, Faizolahi K, Darvish J, Safi K, Brito JC (2019) The species diversity, distribution and conservation status of the terrestrial mammals of Iran. J Mammal 100:55-71

Uno R, Doko T, Ohnishi N, Tamate HB (2015) Population genetic structure of the Asian Black Bear (Ursus thibetanus) within and across management units in northern Japan. Mamm Study 40:231-244

Waits LP, Talbot SL, Ward RH, Shields GF (1998) Mitochondrial DNA phylogeography of the North American Brown Bear and Implications for Conservation. Conserv Biol 12:408-417

Wozencraft WC (2005) Order Carnivora. In: Wilson DE, Reeder DM (eds) Mammal species of the world: a taxonomic and geographic reference, 3rd edn. John Hopkins University Press, Baltimore, pp 532-628

Wu J, Kohno K, Mano S, Fukumoto Y, Tanabe H, Hasegawa M, Yonezawa T (2015) Phylogeographic and demographic analysis of the Asian black bear (Ursus thibetanus) based on mitochondrial DNA. PLoS ONE 10(9):e0136398. https://doi.org/10.1371/journ al.pone. 0136398

Zachos FE, Otto M, Unici R, Lorenzini R, Hartl GB (2008) Evidence of a phylogeographic break in the Romanian brown bear (Ursus arctos) population from the Carpathians. Mamm Biol 73:93-101

Ziaie H (2008) A Field Guide to the Mammals of Iran, 2nd edn. Iranian Wildlife Center, Tehran (in Persian)

Zwickl DJ (2006) Genetic algorithm approaches for the phylogenetic analysis of large biological sequence datasets under the maximum likelihood criterion. The University of Texas, Austin 


\section{Affiliations}

Gholam Hosein Yusefi, $^{1,2,3} \cdot$ Leili Khalatbari $^{1,3} \cdot$ Michael J. Jowers $^{1} \cdot$ Hadi Fahimi $^{3} \cdot$ Vânia Costa ${ }^{1} \cdot$ Mats Björklund $^{2}$. Albano Beja-Pereira ${ }^{1,4}$

1 CIBIO/InBIO, Centro de Investigação em Biodiversidade e Recursos Genéticos, Universidade do Porto, Campus de Vairão, 4485-661 Vairão, Portugal

2 Department of Animal Ecology, Evolutionary Biology

Centre, Uppsala University, Norbyvägen 18D,

75236 Uppsala, Sweden
3 Mohitban Society, No. 111, Moghaddas Ardebili str., Tehran 19859-14747, Iran

4 Department of Geosciences, Environment and Spatial Planning, Faculty of Sciences, University of Porto, Rua do Campo Alegre, 4169-007 Porto, Portugal 